\title{
Examining Character Recognition and Recall Skills of CFL beginner Learners under Four different Approaches
}

\author{
Caitríona Osborne \\ Dublin City University \\ caitriona.osborne5@mail.dcu.ie
}

\begin{abstract}
The following paper presents an action research project investigating four approaches to teaching Chinese as a foreign language (henceforth CFL) to beginner learners in an Irish secondary school over a period of 16 weeks. Around 85 participants were divided into four groups and were taught Chinese via one method of rote memorisation, delayed character introduction, character colour-coding, or a unity curriculum approach respectively. The fourth group acted as a comparative group, and focused on all four skills of reading, writing, speaking, and listening. Participants were taught for two one-hour classes per week and each group covered the same material, including learning 107 Chinese words and their characters. Upon completion of the 16 weeks of teaching, participants were presented with identical recognition and recall tests, whereby higher results in each group reveal effectiveness in a given teaching approach, and provided written feedback detailing their learning experience in the form of a questionnaire. It was found from the questionnaires that all participants felt that learning Chinese was challenging, particularly the characters. While all groups struggled to provide correct answers in the recognition and recall tests, the character colour-coding group coped best in providing the highest percentage of correct answers in both tests. At the same time, all groups agreed that more time spent learning would have allowed for more favourable outcomes. It is hoped that the current study will encourage further research relating to character-teaching methods, with particular reference to using colour, as well as providing some possible guidelines for a future Irish secondary school Chinese language course that is currently in the planning stage. These may include guidelines not only relating to the use of colour when teaching characters,
\end{abstract}


but also in relation to the amount of time spent learning Chinese both inside and outside the classroom.

Keywords: Chinese as a foreign language; Chinese character recall; Chinese character recognition; Chinese characters

\section{Introduction}

A number of researchers (e.g. Everson, 1998; Zhang, Lu, \& Lu, 2013; Shu, 2003) have identified many difficulties faced by beginners learning CFL. Firstly, CFL learners are required to master the four tones of Chinese (Shi, 2016; Abraham, 2013). While learning Chinese grammar may not pose many challenges due to the lack of its complexity with no morphological changes in tense, number, person, gender, and case (Liu, 2003), the writing system of the Chinese language is certainly taxing for a beginner learner (Xing, 2006; Everson \& Shen, 2010; Hoenig, 2009; McNaughton \& Ying, 1999). Dictionaries report approximately 55,000 characters in existence (Yin, 2016); however, knowing around 3,500 of these characters is sufficient to read and understand around 99 percent of Chinese books, newspapers and magazines (Shu, Chen, Anderson, Wu, \& Xuan, 2003). Of course, attempting to learn a new writing system as vast as Chinese is a particular challenge to learners and is seen to take up almost half of a beginner's learning time (Allen, 2008; Osborne, 2016). Previous research (e.g. McNaughton \& Ying, 1999; Yin, 2016; Flaws, 1998) has also shown that meaning and pronunciation of new characters are unclear to a learner due to the fact that it is unknown whether the character was formed on the basis of meaning or pronunciation or both.

It has been demonstrated from the literature that CFL can pose many challenges to beginner learners, particularly when it comes to developing reading and writing skills. Some researchers highlight the suggestion of abandoning the instruction of characters (e.g. Allen, 2008; Shen, 2015; Ye, 2013), however in a counter argument, others state that focusing on writing the characters can also strengthen reading skills (Guan, Liu, Chan, Ye, \& Perfetti, 2011; Chang, Xu, Perfetti, Zhang, \& Chen, 2014; Longcamp et al., 2008). Therefore, if the action of learning characters requires much of a learner's time, yet is seen to be beneficial in other areas of learning CFL, the researcher wished to explore the effects of various teaching approaches on the recall and recognition abilities of beginner learners. 
Another source of motivation for conducting the current research lies within the Irish context of teaching CFL. Currently, in addition to the Transition Year Chinese optional module for fourth-year Irish secondary school students, a Short Course in Chinese Language and Culture aimed at years one to three introduces young learners to the basics of Chinese language and culture (National Council for Curriculum and Assessment, 2016). This Short Course was introduced as part of the Minister's policy to reform the entire Junior Cycle Curriculum and is 100 hours in duration, whereas a full foreign language course to be assessed in the State exams comprises of a minimum of 200 hours (Curriculum Online, 2018).

A ten-year plan is currently underway which aims to include CFL as an optional subject for students to take for the final school examinations (Department of Education and Skills, 2017). This introduction of Chinese to the State exams curriculum is one element in an ambitious and broad national initiative entitled Languages Connect - Ireland's Strategy for Foreign Languages in Education 2017-2026. In this initiative, a link between the Short Course and the proposed new Leaving Certificate is advocated.

Of course, as this will be the first introduction of CFL to the State exams curriculum, it is imperative that the character-teaching methods adopted in Irish schools will not only ensure the students can pass these exams, but also be provided with a strong foundation for future CFL learning. In addition to this, it is vital that the teaching approaches adopted will allow prospective students to achieve sufficient exit levels to compete with their peers in other English-speaking countries such as Australia, the US and the UK, whereby formally-tested CFL school curricula have already been established.

\section{Studies in teaching CFL}

The complexity and volume of Chinese characters as highlighted in Section 1 suggest that characters do take up much of a beginner learner's time. Researchers such as Allen (2008), Shen (2015), and Ye (2013) write of the existing debate on whether spending so much time learning characters is actually beneficial to overall language learning. Allen (2008) makes reference to the ever-increasing and advanced technologies that aid character writing in communication, and questions the need to spend time learning characters. Of course, studies (Guan, et al., 2011; Chang, et al., 2014; Longcamp, et al., 2008) have proven that writing 
characters does benefit other areas of CFL learning such as reading; while Randall (2007), Dehn (2008), and Guan et al. (2011) highlight that the repetition of writing characters aids comprehension of these characters. Other researchers, such as Packard (1990) and Ye (2013), suggest that a delay in teaching characters will aid beginners in their long-term learning of CFL.

Due to the number of debates currently ongoing in the field of teaching CFL with regards to methods of teaching and timing of the introduction of characters to beginner learners, the researcher wished to identify the effectiveness of approaches to teaching characters in the form of evaluations testing recognition and recall skills of participants. In identifying the higher percentages of correct answers provided by the groups in each section, the comparative effectiveness of each teaching approach could be investigated. Additionally, the researcher wished to become aware of each group's thoughts surrounding their learning experience under their assigned teaching approach, which will be discussed in further sections.

\subsection{Four teaching approaches}

The researcher used four teaching approaches in the current study and measured the comparative effectiveness when teaching beginner learners, with particular focus on character recognition and recall skills. Participants were split into four groups and were taught CFL for 16 weeks via one of the following approaches according to their group.

The first group learned Chinese characters via rote memorisation (henceforth RM). RM is a teaching method based on the concept of repetition. This repetition leads to comprehension and memorisation, however if sufficient focus is not applied, the repeated items will only be stored in the short-term memory (Dehn, 2008; Greenberg, 2000). In the current research, the researcher trained the participants to conduct RM correctly and controlled the environment, allowing for focus to be applied when writing the characters repeatedly. RM is a popular teaching method in China for teaching Chinese characters and other subjects including maths (e.g. Chan, 1999; Kember, 1996). It is also worth noting that in many countries, including Ireland, this method of learning is unpopular due to beliefs that rote learning is ineffective (Dimmock, 2000). However, it is nonetheless seen that when it comes to Chinese characters, 
there is a need for a certain amount of repetition for successful learning (Xu \& Padilla, 2013; Winke, 2013), so this method was included in the study. Motivational factors of all groups were also recorded and taken into consideration in the classroom, and further information on this will be reported in a later paper.

The second group learned Chinese characters through delayed character introduction (henceforth $\mathrm{DCl}$ ). This method attempts to lessen the workload for beginners by delaying learning the characters until after three weeks, when the learners have had sufficient time to grasp the basics of the language (Packard, 1990). In a study carried out by Packard (1990), a group of participants learning characters via $\mathrm{DCl}$ outperformed a control group in various language tasks, including the ability to discriminate syllables and speak more fluently. In Ye's (2013) paper, it is seen that there are reservations among instructors and students alike with regards to the possible benefits of $\mathrm{DCl}$, despite Packard's (1990) positive results in his research. In the current study, the researcher first taught this group via pinyin (the Romanization of standard Chinese) before introducing the characters in the fourth week of teaching, and after this continued to teach the characters with a delay of approximately one week. As the literature surrounding $\mathrm{DCl}$ is somewhat conflicting, the researcher wished to ascertain the effects of this method on beginner learners' written ability in recognising and recalling characters in relation to the other approaches reported in this paper.

The third group learned Chinese characters through character colour-coding (henceforth CCC). Using colour when teaching is quite popular (e.g. Winsor, 2009; Karges-Bone, 2010; Jensen, 2008), and can particularly assist children when learning new items (Jensen, 2008). It is seen that this use of colour in lessons, including language learning, can aid a learner in terms of heightened concentration, promoting understanding of the lesson, and memorisation of new items (Dzulkifli \& Mustafar, 2013). Chinese characters have also been presented using colour in some online Chinese dictionaries to provide a physical marker for the tones of characters (e.g. Dummit, 2008; Boyce, 2010). While the benefits of using colour when teaching are well-established through various researchers (e.g. Spence, Wong, Rusan, \& Rastegar, 2006; Smilek, Dixon, Cudahy, \& Merikle, 2002; Wichmann, Sharpe, \& Gegenfurtner, 2002; Hall \& Hanna, 2004), there have been no studies examining the effect of using colour to learn Chinese characters, thus the researcher wished to include this in the research. The 
colours green, black, blue, and red were used for tones one to four respectively, while characters with no tone were written with a pencil.

Finally, the Comparative group studied via a unity curriculum approach that is currently used in Irish third-level institutions today. Third-level institutions were the focus as a Stateexamined CFL curriculum does not yet exist in Irish secondary schools. When the module descriptors were consulted and various module instructors were interviewed, it was found that no specific focus was placed on methods for learning characters in these courses. Instead students focused equally on their reading, writing, speaking, and listening skills. As a result, the researcher adopted this approach in the Comparative group to analyse the current norm against RM, DCl, and CCC in terms of each group's ability to recognise and recall characters. When participants in this group were told to learn the characters as homework, they were not given specific instruction of a particular method as in the other groups.

\section{Methodology}

The current research is based on the process of action research, which is fundamentally different from a lab-based experiment that takes place in a fully controlled environment. Action research is a systematic inquiry carried out by teachers or any other personnel with an established interest in teaching and learning processes or environment (Mertler, 2017). The goal of action research is to examine closely how a school operates, and how the processes of teaching and learning occur with the aim of improving teaching practices. Sagor (2000) and Bradbury (2015) note the seven steps in an action research project. They are: (1) choosing a focus; (2) analysing previous research; (3) identifying research questions; (4) collecting valid and reliable data; (5) analysing collected data; (6) reporting results; (7) using this information to enhance teaching. It is a complex and established procedure, yet Crooke (1993) highlights controversy surrounding teacher concerns that certain claims may not necessarily be replicated in various classrooms. However, in the current research, the researcher deemed this procedure to be most suitable for investigating students' learning outcomes and day-today attitudes towards the teaching approaches. The researcher was therefore able to observe the CFL classroom in a real-life situation. 
The participants were transition year students in an Irish secondary school aged between 14 and 16. Most of the participants spoke English as their first language and all participants had no prior knowledge of Chinese. They were divided randomly into four groups and were taught via $\mathrm{RM}, \mathrm{DCl}, \mathrm{CCC}$, or the current norm of Irish third-level institutions depending on their group. Although each group's teaching approach varied, the content of each class remained the same. For example, the researcher taught all groups separately for two one-hour classes per week, each group was introduced to the same 107 words and their characters over the 16 weeks, participants used the same textbook, and they conducted the same practice exercises and evaluations. In other words, any variable outside their relevant teaching approaches was regulated by the researcher.

The participants were taught using the New Practical Chinese Reader: Textbook 1 (Liu, et al., 2007). This textbook is recommended through the Confucius Institute headquarters and contains content in line with the introductory Chinese language proficiency (HSK) test (Liu, et al., 2007). This textbook is widely popular in universities (Zhou, 2011), and as it is aimed at young adults learning through English, it was deemed appropriate for the current research.

The current research adopted a mixed methods approach. Firstly, the quantitative methods in the form of the written evaluations measured the participants' ability to correctly recognise and recall various characters. Secondly, the qualitative methods in the form of a feedback questionnaire gathered participants' thoughts on their learning experience.

In terms of the quantitative data, the participants were presented with a written evaluation after 16 weeks of teaching. In the recognition section, ten Chinese words written in characters were presented and participants were required to write (1) the translation of the character(s) into English and (2) the pinyin of the character(s). In the recall section, ten English words were presented. Participants were required to provide the Chinese character(s) for the corresponding word. The effectiveness of each approach was measured on the results of each group's performance in the recall and recognition tests. In other words, if a group scored higher than the others in either the recall or recognition tests, then this approach would be deemed to be more effective than the others in this study. The results of this are displayed in Section 4. 
The qualitative methods collected feedback from the participants on their learning experience in the form of a questionnaire presented upon conclusion of teaching. The participants were asked: (1) if they found learning CFL challenging, (2) what the most difficult aspect of learning CFL was and; (3) what they could have done to improve their learning. Questions two and three were open-ended, meaning the participants had the opportunity to transcribe their answers without influence.

\section{Results}

The following section will present first the quantitative results followed by the qualitative results as highlighted in the previous section. It is worth noting that all variations of answers were recorded and can be seen in the following sections.

\subsection{Results from the recognition and recall tests}

Figure 1 shows the results in percentages for each group's ability to recognise ten Chinese words in characters by supplying the English translation and pinyin.

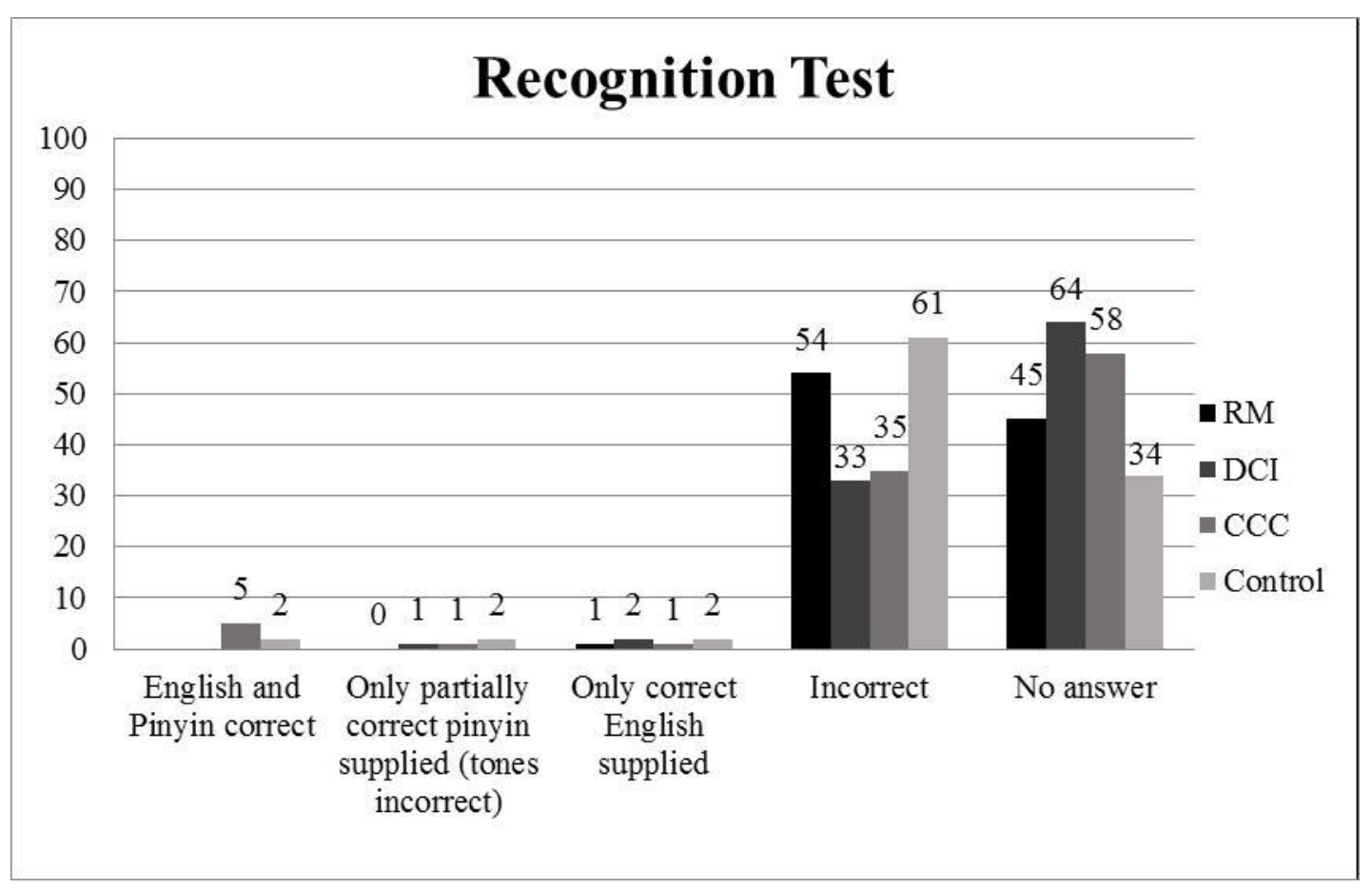

Figure 1: Results (in percentages) of ability to recognise characters after 16 weeks 
What is first apparent is the lack of fully correct answers. Only five percent of the CCC group and two percent of the Comparative group answers were correct in English translation and pinyin. The RM and $\mathrm{DCl}$ groups did not manage to supply any fully correct answers.

The vast majority of each group's answers are distributed among the 'incorrect' and 'no answer' columns. While the majority of the RM and Comparative groups answered incorrectly (54 percent and 61 percent respectively), the DCI group and the CCC group also had relatively high percentages of incorrect answers with 33 percent and 35 percent respectively. These results show that although attempted, the participants could not provide any fully correct answers.

Furthermore, the $\mathrm{DCl}$ and $\mathrm{CCC}$ groups supplied 64 percent and 58 percent of blank answers respectively. The RM and Comparative groups also had 45 percent and 34 percent blank answers respectively, showing that a large percentage of answers, particularly in the $\mathrm{DCl}$ and CCC groups, could not even be attempted by participants.

On a smaller scale, one percent of the $\mathrm{DCl}$ and CCC groups and two percent of the Comparative group were able to supply only partially correct pinyin with incorrect tones. Secondly, one percent of the RM and CCC groups and two percent of the $\mathrm{DCl}$ and Comparative groups provided only the correct English translation of the characters.

Figure 2 shows the results in percentages for each group's ability to recall characters after being presented with ten English words. 


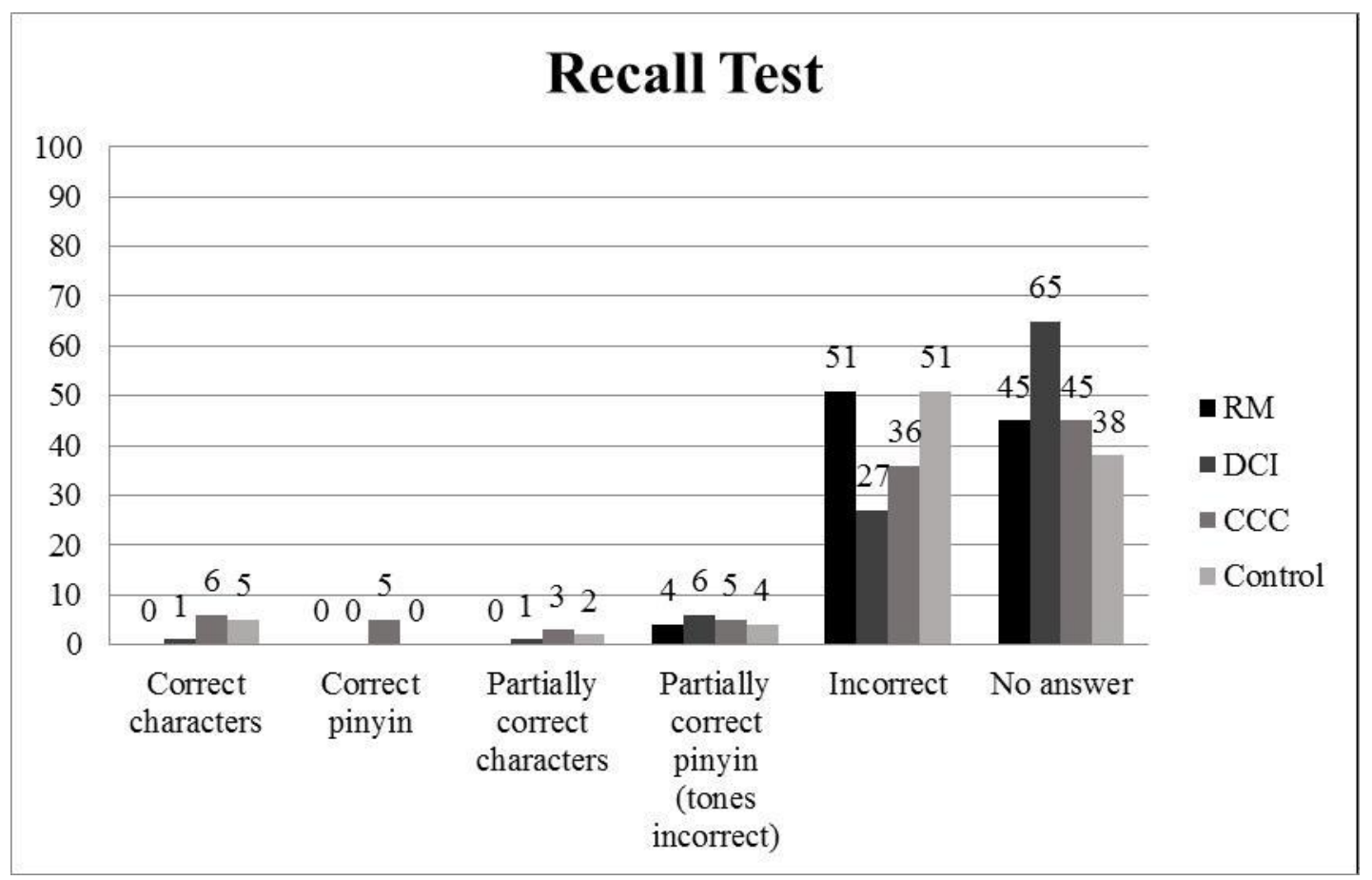

Figure 2: Results (in percentages) of ability to recall characters after 16 weeks

From the above, it is seen that one percent, six percent, and five percent of the $\mathrm{DCl}, \mathrm{CCC}$, and Comparative groups' answers respectively were written with correct characters. While the CCC group scored the highest percentage of correct characters, the result still does not compare with the 'incorrect' and 'no answer' columns as in the recognition results.

The figure shows that 51 percent, 27 percent, 36 percent, and 51 percent of the answers provided by the $\mathrm{RM}, \mathrm{DCl}, \mathrm{CCC}$, and Comparative groups respectively were incorrect and that 45 percent, 65 percent, 45 percent, and 38 percent of answers provided by the RM, DCI, CCC, and Comparative groups respectively were not attempted.

Only five percent of the $\mathrm{CCC}$ group answered using correct pinyin, while none of the remaining groups provided any correct pinyin. Four percent of the RM and Comparative groups, six percent of the $\mathrm{DCl}$ group and five percent of the CCC group answered using pinyin with incorrect tones. 
Finally, some answers were written with only slight errors. In this instance, one percent of the $\mathrm{DCl}$ group, three percent of the CCC group, and two percent of the Comparative group answers were written with partially correct characters.

The above results will be discussed further in the Discussion section.

\subsection{Feedback provided by four groups}

The following section provides an insight to each group's thoughts surrounding their learning experience. The groups were each asked: (1) was learning CFL challenging?; (2) what was the most difficult aspect of learning CFL?; (3) what could you have done to improve your learning? The following displays the answers of each group and will be discussed further in the Discussion section.

Firstly, the results below highlight the top answer in percentages of each group when asked if they found learning CFL to be challenging.

\begin{tabular}{|l|l|l|l|l|}
\hline & RM & DCl & CCC & Comparative \\
\hline Found CFL challenging & 90 & 100 & 95 & 94 \\
\hline
\end{tabular}

Table 1: Participants' answers (in percentages) when asked if they found learning CFL to be challenging

Almost all participants found that learning CFL was a challenging task. The DCl group appear to have found learning CFL more difficult than their peers, whereas the RM group, although with a very high percentage, group have provided the lowest percentage of 'yes' answers.

The second question aims to further explore this first question and pinpoint the most challenging aspect of learning CFL for each group. The top answers of each group are listed below. However there were, naturally, a variety of alternative answers which can be viewed in the appendix (A). 


\begin{tabular}{|l|l|l|l|l|}
\hline & RM & DCl & CCC & Comparative \\
\hline Characters most difficult & 64 & 52 & 75 & 75 \\
\hline
\end{tabular}

Table 2: Participants' top answers (in percentages) when asked to write the most difficult aspect of learning Chinese

Although the question was open-ended, all groups highlighted the difficulty with learning characters. The $\mathrm{DCl}$ group appeared to struggle comparatively less than their peers, with the CCC and Comparative groups providing the highest percentages.

The final question was included to ascertain if the participants believed they could have approached learning CFL differently in order to allow for more successful learning outcomes.

\begin{tabular}{|l|l|l|l|l|}
\hline & RM & DCI & CCC & Comparative \\
\hline Should have spent more time studying & 68 & 32 & 45 & 64 \\
\hline
\end{tabular}

Table 3: Participants' top answers (in percentages) when asked to identify further efforts they could have made to improve their learning

Once again, all of the groups share the same top answer in stating that more time spent learning CFL would have helped them to improve their learning outcomes. The RM group's answers account for the highest percentage in this category, while the $\mathrm{DCl}$ group provide the lowest percentage, albeit the majority answer for this group.

This result actually highlights two items. Firstly, it can be seen that the majority of participants believed they did not study enough to allow for success in the evaluation. Secondly, each groups' answers support previous research in stating indirectly that learning CFL and Chinese characters does take time (e.g. Allen, 2008), and furthermore, this time spent learning CFL is not only beneficial but necessary for successful acquisition (e.g. Guan, et al., 2011; Chang, et al., 2014; Longcamp, et al., 2008; Randall, 2007; Dehn, 2008).

Of course, participants of each group also highlighted multiple other tasks they could have completed to improve their learning. These are highlighted in appendix (B). 


\section{Discussion}

The current study set out to examine the effectiveness of four teaching approaches on CFL beginner learners in terms of their ability to recognise and recall characters after 16 weeks of learning CFL. Furthermore, the researcher collected participant feedback upon completion of the study in order to ascertain whether or not they found learning CFL to be challenging, what the most difficult aspect of learning CFL was, and actions they could have taken to improve their learning.

Firstly, in testing the recognition skills of participants, we see that the majority of answers provided by all groups fall under the categories of 'incorrect' or 'no answer'. This is in line with the questionnaire results showing that not only did the majority of all groups find Chinese to be challenging, with particular reference to the characters, but also the acknowledgement by the majority of all groups that more time spent learning the characters would have helped to improve their learning outcomes.

The CCC and Comparative groups scored comparatively highest, although the percentages were much lower than the 'incorrect' and 'no answer' categories. Interestingly, although the CCC group had the highest percentage among all groups stating that they found the characters to be most difficult, they also provided the second-lowest percentage of answers admitting that they should have spent more time studying. Therefore, although the CCC group may have found learning the characters to be challenging, a combination of using colour to learn characters and perhaps putting in more time than other groups outside of the classroom may have allowed for this comparatively higher percentage. The Comparative group also had the same percentage of answers stating that they found learning the characters to be difficult, while they provided the second-highest percentage of responses highlighting that they should have dedicated more time to studying, even after obtaining the second-highest percentage of correct answers in the recognition section. This may be due to the fact that the group focused equally on developing skills of reading, writing, speaking, and listening without a specific focus on characters. Thus, they may have felt that not enough time was spent learning the characters inside or outside the classroom. 
In the feedback questionnaire, some of the RM group described having trouble focusing at times, which may account for low results in the recognition section. As mentioned in Section 2.2, if sufficient focus is not applied when learning via RM, then the items will only be stored in the short-term memory and will subsequently be more difficult to recall. A portion of the $\mathrm{DCl}$ group found everything about learning Chinese to be most difficult, and stated that they should have paid more attention in class. These items may also account for their relatively poorer results and highlight that paying attention during class time is of course essential for learning Chinese.

Overall, these results are intriguing as each teaching approach was specifically included in the research to tackle the difficulty of learning Chinese characters. However, after 16 weeks of learning CFL, the participants still find the Chinese writing system to be one of the most difficult aspects. This result is also consistent with previous literature surrounding CFL learning. The encouraging finding is that the $\mathrm{DCl}$ group has the lowest percentage of answers compared to the other three groups when referring to the difficulty of learning characters. Therefore, the method of $\mathrm{DCl}$ may reduce the anxiety of learning Chinese characters.

Secondly, in the recall test, the highest percentage of answers for each group fell under the 'incorrect' and 'no answer' categories, which is again in line with the questionnaire results as discussed above.

The CCC and Comparative groups have scored the highest correct answers, with CCC coming top. These findings correlate with those above in that the CCC group, despite recognising the difficulty in learning the characters and the amount of time needed to spend learning CFL, have perhaps been able to more effectively learn the characters through the use of colour. Some percentages of the CCC group also stated that everything was difficult when it came to learning Chinese and some mentioned they should have spent more time learning the characters. This still highlights the potential benefit for CCC. That is, even though participants of this group identified flaws in their personal learning, they were still able to achieve relatively higher results than their peers. In addition, the Comparative group have still been able to provide some correct characters despite mentioning difficulties in learning the characters and admitting they should have spent more time studying. This highlights potential 
benefits of the Comparative approach once sufficient time has also been spent learning characters under this approach.

The CCC group are also the group who had the highest percentage of partially correct characters and correct pinyin, which shows that they were at least attempting to write the characters more frequently than other groups as well as showing capability to remember the correct pronunciation of Chinese characters. Other groups also attempted to write the pinyin of various characters, albeit with errors, presumably because they could not attempt to write the correct character. The $\mathrm{DCl}$ group provided the lowest percentage of answers in the questionnaire when stating that the characters were the most difficult aspect of learning Chinese, and the group has attempted to answer with pinyin more often than other groups in the recall section, albeit with the highest percentage of incorrect tones. As the participants of this group had been focusing only on pinyin before being introduced to characters, it may suggest that their focus was on pinyin rather than devoting enough time to learning the characters, as some have highlighted in the questionnaires. At the same time, their skills in using pinyin appear to be suffering overtime as a result of increasing the cognitive workload with characters.

It was hypothesised that the RM group would have scored the highest in terms of the ability to recognise and recall characters due to the focus applied during the process of rote memorisation; however the group have actually scored quite poorly in both sections. It is no surprise, therefore, that they provided the highest percentage of answers in stating that they should have spent more time learning. This supports previous findings in that not only are the characters difficult to learn for CFL beginners, but much time and focus is also needed to be spent learning these characters in order for successful acquisition to occur. Students also may have felt that they could not afford to invest the appropriate time to achieve higher results. While literature still advocates that an element of rote learning is required when learning Chinese characters as mentioned previously, it is unsurprising that many deem rote memorisation to be ineffective when results such as the ones reported in this study are achieved. However, it is quite likely as demonstrated in the current research, that insufficient time was spent learning outside of the classroom. 


\section{Conclusion}

The results show that all groups struggled with both recognising and recalling characters; however the CCC group did score the highest in both sections, suggesting that using colour when learning Chinese characters may be beneficial to enhancing a beginner learners' recognition and recall skills. Still, it is seen that the 'correct' answer percentages provided by the CCC group are quite low. Therefore, future research is necessary to further explore the effectiveness of using colours when learning characters. The majority of each group were in agreement that learning CFL was a challenging task, and that learning the characters was the main difficulty (responses in appendices).

In addition to the above, all participants agreed that they should have spent more time learning CFL, which supports previous research that time is also a factor when learning Chinese characters.

The current study was motivated partly by the notion that the characters are indeed one of the more difficult aspects when learning Chinese. In attempting to seek effective approaches for teaching characters to enhance recognition and recall skills, it was not only proven that beginner learners do find Chinese characters to be the most challenging aspect of learning Chinese, but also that colour-coding characters may be beneficial for the acquisition of characters, and a delay in the introduction of characters may reduce anxiety in beginner learners. As a ten-year plan is currently underway in Ireland that will see CFL as an optional subject for students to be examined during their final school examinations, it may be further explored how colour might affect the learning outcomes of CFL beginner learners, and if this method could be incorporated to the proposed curriculum for Irish secondary schools and in other CFL curricula around the world. In addition to this, it is apparent from the participants' feedback, and from previous research, that much time must be dedicated to the learning process in order for skills of character recognition and recall to be developed. Therefore, a further criterion for this proposed CFL curriculum may suggest a guideline for classroom contact hours and time spent learning Chinese outside of school hours. 


\section{References}

Abraham, W. (2013). Chinese for dummies (2nd ed.). New Jersey: John Wiley \& Sons, Inc.

Allen, J. R. (2008). Why learning to write Chinese is a waste of time: A modest proposal. Foreign Language Annals, 41(2), 237-251. doi:10.1111/j.1944-9720.2008.tb03291.x

Boyce, C. (2010). Chinese as it is: A 3D sound atlas with first 1000 characters!. Indianapolis: Dog Ear Publishing.

Chan, S. (1999). The Chinese learner - a question of style. Education + Training, 41(6), 294305. doi:10.1108/00400919910285345

Chang, L., Xu, Y., Perfetti, C. A., Zhang, J., \& Chen, H. (2014). Supporting orthographic learning at the beginning stage of learning to read Chinese as a second language. International Journal of Disability, Development and Education, 61(3), 288-305. doi:10.1080/1034912X.2014.934016

Crookes, G. (1993). Action research for second language teachers: Going beyond teacher research. Applied Linguistics, 14(2), 130-144.

Curriculum Online. (2018). Overview: Course. Retrieved from https://www.curriculumonline.ie/Junior-cycle/Junior-Cycle-Subjects/Modern-ForeignLanguages/Overview-Course

Dehn, M. J. (2008). Working memory and academic learning: Assessment and intervention. New Jersey: John Wiley \& Sons, Inc.

Department of Education and Skills. (2017). 19 April, 2017 - Minister Bruton to prioritise teaching of foreign languages. Retrieved from http://www.education.ie/en/PressEvents/Press-Releases/2017-Press-Releases/PR17-04-19.html

Department of Education and Skills. (2018). Languages Connect - Ireland's Strategy for Foreign Languages in Education 2017-2026. Retrieved from https://www.education.ie/en/Schools-Colleges/Information/Curriculum-andSyllabusForeign-Languages-Strategy/fls languages connect strategy.pdf

Dimmock, C. A. J. (2000). Designing the Learning-centred School: A Cross-cultural Perspective. London and New York: Taylor \& Francis.

Dummitt, N. (2008). Chinese through tone \& color. China: Hippocrene Books.

Dzulkifli, M. A., \& Mustafar, M. F. (2013). The influence of colour on memory performance: A review. The Malaysian Journal of Medical Sciences, 20(2), 3-9.

Everson, M. E. (1998). Word recognition among learners of Chinese as a foreign language: Investigating the relationship. Modern Language Journal, 82(2), 194. Retrieved from http://search.ebscohost.com/login.aspx?direct=true\&db=ufh\&AN=812946\&site=ehos t-live

Everson, M., \& Shen, H. (Eds.). (2010). Research among learners of Chinese as a foreign language. USA: Chinese Language Teachers Association.

Flaws, B. (1998). Teach yourself to read modern medical Chinese: A step-by-step workbook and guide. USA: Blue Poppy Press.

Greenberg, K. H. (2000). The cognitive enrichment advantage teacher handbook. USA: KCD Harris \& Associates Press.

Guan, C., Liu, Y., Chan, D., Ye, F., \& Perfetti, C. (2011). Writing strengthens orthography and alphabetic-coding strengthens phonology in learning to read Chinese. Journal of Educational Psychology, 103(3): 509-522. 10.1037/a0023730

Hall, R. H., \& Hanna, P. (2004). The impact of web text-background color combination on readability, retention, aesthetics and behavioural intention. Behaviour \& Information Technology, 23(3), 183-195. 
Hoenig, A. (2009). Chinese characters: Learn \& remember 2,178 characters and their meanings. New York: EZChinesey.com.

Jensen, E. (2008). Brain-based learning: The new paradigm of teaching. USA: Corwin Press.

Karges-Bone, L. (2010). Differentiated pathways of the brain: Using sensory and genderbased teaching to shape your elementary curriculum. USA: Lorenz Educational Press.

Kember, D. (1996). The intention to both memorise and understand: Another approach to learning? Higher Education, 31(3), 341-354. Retrieved from http://www.jstor.org/stable/3447651

Liu, X. (2003). New practical Chinese reader: Textbook 1. China: Beijing Language and Culture University Press.

Longcamp, M., Boucard, C., Gilhodes, J., Anton, J., Roth, M., Nazarian, B., \& Velay, J. (2008). Learning through hand- or typewriting influences visual recognition of new graphic shapes: Behavioral and functional imaging evidence. Journal of Cognitive Neuroscience, 20(5), 802-815.

McNaughton, W., \& Ying, L., (Eds.). (1999). Reading and writing Chinese (2nd ed.). Hong Kong: Tuttle Publishing.

Mertler, C. A. (2017). Action research: Improving schools and empowering educators (5th ed.). USA: SAGE Publications, Inc.

National Council for Curriculum and Assessment (NCCA). (2016). Rationale. Retrieved from http://www.curriculumonline.ie/Junior-cycle/Short-Courses/Chinese/Rationale

Osborne, C. (2016). Chinese in the classroom: Initial findings of the effects of four teaching methods on beginner learners. Journal of Second Language Teaching and Research, 5(Special Issue), 202-225.

Packard, J. L. (1990). Effects of time lag in the introduction of characters into the Chinese language curriculum. Modern Language Journal, 74(ii), 167-175.

Randall, M. (2007). Memory, psychology and second language learning. Amsterdam/Philadelphia: John Benjamins Publishing Company.

Shen, H. (2015). Chinese L2 literacy debates and beginner reading in the United States. In M. Bigelow, \& J. Ennser-Kananen (Eds.), The Routledge handbook of educational linguistics (pp. 276-288). New York and London: Routledge.

Shi, D. (2016). Mandarin. In C. Sin-wai (Ed.), The Routledge encyclopedia of the Chinese language (pp. 579-604). London and New York: Routledge.

Shu, H. (2003). Chinese writing system and learning to read. International Journal of Psychology, 38(5), 274-285.

Shu, H., Chen, X., Anderson, R. C., Wu, N., \& Xuan, Y. (2003). Properties of school Chinese: Implications for learning to read. Child Development, 74(1), 27-47. doi:10.1111/14678624.00519

Smilek, D., Dixon, M. J., Cudahy, C., \& Merikle, P. M. (2002). Synesthetic color experiences influence memory. Psychological Science, 13(6), 548-552.

Spence, I., Wong, P., Rusan, M., \& Rastegar, N. (2006). How color enhances visual memory for natural scenes. Psychological Science, 17(1), 1-6.

Wichmann, F. A., Sharpe, L. T., \& Gegenfurtner, K. R. (2002). The contributions of color to recognition memory for natural scenes. The Journal of Experimental Psychology: Learning, Memory, and Cognition, 28(3), 509-520.

Winke, P. (2013). An investigation into second language aptitude for advanced Chinese language learning. Modern Language Journal, 97(1), 109-130. doi:10.1111/j.15404781.2013.01428.x 
Winsor, P. (2009). Language Experience Approach to Literacy for Children Learning English. Canada: Portage \& Main Press.

Xing, J. (2006). Teaching and learning Chinese as a foreign language: $A$ pedagogical grammar. Hong Kong: Hong Kong University Press.

Xu, X., \& Padilla, A. M. (2013). Using meaningful interpretation and chunking to enhance memory: The case of Chinese character learning. Foreign Language Annals, 46(3), 402422. doi:10.1111/flan.12039

Ye, L. (2013). Shall we delay teaching characters in teaching Chinese as a foreign language? Foreign Language Annals, 46(4), 610-627. doi: 10.1111/flan.12049

Yin, J. J. (2016). Chinese characters. In S. Chan (Ed.), The Routledge encyclopedia of the Chinese language (pp. 51-63). London and New York: Routledge.

Zhang, J., Lu, X., \& Lu, X. (2013). Variability in Chinese as a Foreign Language Learners' Development of the Chinese Numeral Classifier System. The Modern Language Journal, 97, 46-60. Retrieved from http://www.jstor.org.dcu.idm.oclc.org/stable/23361911

Zhou, M. (2011). Globalization and language order: Teaching Chinese as a foreign language in the united states. In L. Tsung, \& K. Cruickshank (Eds.), Teaching and learning Chinese in global contexts: CFL worldwide (pp. 131-150). London and New York: Continuum International Publishing Group. 


\section{Appendix A: Excerpts from question two}

\begin{tabular}{|l|l|l|l|l|l|l|l|}
\hline & $\begin{array}{l}\text { "Keeping } \\
\text { focused" }\end{array}$ & "Pinyin" & $\begin{array}{l}\text { "Sentence } \\
\text { structure" }\end{array}$ & $\begin{array}{l}\text { "Learning } \\
\text { it" }\end{array}$ & "Everything" & "Understanding & "Translation" \\
it" & & & & \\
\hline RM & 8 & 8 & 4 & 4 & 4 & 4 & 4 \\
\hline
\end{tabular}

Table 4: All other RM answers (in percentages) when asked to write the most difficult aspect of learning Chinese

\begin{tabular}{|l|l|l|l|l|l|}
\hline & "Learning it" & "Everything" & "Pinyin" & "Pronunciation" & "Stroke orders" \\
\hline DCl & 18 & 18 & 4 & 4 & 4 \\
\hline
\end{tabular}

Table 5: All other DCl answers (in percentages) when asked to write the most difficult aspect of learning Chinese

\begin{tabular}{|l|l|l|l|}
\hline & "Everything" & "Translation" & "Tests" \\
\hline CCC & 15 & 5 & 5 \\
\hline
\end{tabular}

Table 6: All other CCC answers (in percentages) when asked to write the most difficult aspect of learning Chinese

\begin{tabular}{|l|l|l|l|l|}
\hline & "Everything" & "Pinyin" & "Pronunciation" & "Too much to learn" \\
\hline Comparative & 10 & 5 & 5 & 5 \\
\hline
\end{tabular}

Table 7: All other Comparative answers (in percentages) when asked to write the most difficult aspect of learning Chinese 
Appendix B: Excerpts from question three

\begin{tabular}{|l|l|l|l|l|l|l|l|}
\hline & $\begin{array}{l}\text { "Pay } \\
\text { attention } \\
\text { in class" }\end{array}$ & $\begin{array}{l}\text { "More } \\
\text { motivation" }\end{array}$ & $\begin{array}{l}\text { "Be } \\
\text { smarter" }\end{array}$ & $\begin{array}{l}\text { "Consistent } \\
\text { learning" }\end{array}$ & "Relax" & "Participate & "Take \\
in class" & $\begin{array}{l}\text { more } \\
\text { seriously" }\end{array}$ \\
\hline RM & 8 & 4 & 4 & 4 & 4 & 4 & 4 \\
\hline
\end{tabular}

Table 8: All other RM answers (in percentages) when asked to identify further efforts they could have made to improve their learning

\begin{tabular}{|l|l|l|l|l|l|l|l|l|}
\hline $\begin{array}{l}\text { attentio } \\
\mathrm{n} \text { in } \\
\text { class" }\end{array}$ & "Nothing" & $\begin{array}{l}\text { "Write } \\
\text { more" }\end{array}$ & $\begin{array}{l}\text { "Attend } \\
\text { more } \\
\text { classes" }\end{array}$ & $\begin{array}{l}\text { "More } \\
\text { interest" }\end{array}$ & $\begin{array}{l}\text { “Ignore } \\
\text { characters" }\end{array}$ & $\begin{array}{l}\text { "Be better } \\
\text { at } \\
\text { languages" }\end{array}$ & $\begin{array}{l}\text { "Don't } \\
\text { know" }\end{array}$ \\
\hline DCl & 14 & 14 & 10 & 10 & 5 & 5 & 5 & 5 \\
\hline
\end{tabular}

Table 9: All other DCl answers (in percentages) when asked to identify further efforts they could have made to improve their learning

\begin{tabular}{|l|l|l|l|l|l|l|l|l|l|}
\hline & $\begin{array}{l}\text { "Learn } \\
\text { characters" }\end{array}$ & $\begin{array}{l}\text { "Pay } \\
\text { attentio } \\
\mathrm{n} \text { in } \\
\text { class" }\end{array}$ & $\begin{array}{l}\text { "More } \\
\text { interest" }\end{array}$ & $\begin{array}{l}\text { "Don't } \\
\text { know" }\end{array}$ & "Everything" & "Clearer & "Try & "Make \\
notes" & $\begin{array}{l}\text { "Slower } \\
\text { different } \\
\text { methods" }\end{array}$ & it fun" & pace" \\
\hline CCC & 15 & 5 & 5 & 5 & 5 & 5 & 5 & 5 & 5 \\
\hline
\end{tabular}

Table 10: All other CCC answers (in percentages) when asked to identify further efforts they could have made to improve their learning 
Examining Character Recognition and Recall Skills of CFL Beginner Learners under Four different Approaches

\begin{tabular}{|c|c|c|c|c|c|c|}
\hline & $\begin{array}{l}\text { "More } \\
\text { interactive" }\end{array}$ & "Nothing" & $\begin{array}{l}\text { "More } \\
\text { interest" }\end{array}$ & $\begin{array}{l}\text { “Don't } \\
\text { know" }\end{array}$ & $\begin{array}{l}\text { "Try } \\
\text { different } \\
\text { methods" }\end{array}$ & $\begin{array}{l}\text { "Make } \\
\text { it fun" }\end{array}$ \\
\hline Comparative & 11 & 5 & 5 & 5 & 5 & 5 \\
\hline
\end{tabular}

Table 11: All other Comparative answers (in percentages) when asked to identify further efforts they could have made to improve their learning 